\title{
INFLUENCE OF IMPERFECTIONS ON THE FLEXURAL RESISTANCE OF STEEL DELTA GIRDERS
}

\author{
Omar Youssef El Masri ${ }^{1, *}$ and Eric M. Lui ${ }^{2}$ \\ 'Popli Design Group, Penfield, NY 14526, USA \\ 1,2 Department of Civil and Environmental Engineering, Syracuse University, NY 13244-1240, USA \\ * (Corresponding author: E-mail: oyelmasr@syr.edu)
}

\section{A B S T RA C T}

Residual stresses and geometrical imperfections are important factors that affect the inelastic lateral-torsional buckling (LTB) capacity of flexural members. In this paper, the influence of the magnitudes of residual stresses and initial geometrical imperfections in the form of member out-of-straightness on the flexural resistance of steel delta girders (SDG) is investigated. Based on test data reported for welded plates and monosymmetric welded I-sections, a residual stress pattern for SDG is proposed. Six different combinations of residual stress and geometrical imperfection magnitudes are then used in a finite element simulation study of a series of SDG under uniform bending and simply-supported boundary conditions. The flexural resistance curves computed for these SDG are compared with one another to demonstrate that both residual stresses and initial member out-of-straightness have a noticeable influence on the moment capacity of SDG, especially in the inelastic LTB region. These curves are also compared against the flexural strength equations provided in the current AISC specifications. The comparison reveals that the AISC equations often over-predict the flexural strength of SDG. An SDG flexural strength reduction factor is then proposed to allow for the design of these SDG using the AISC design equations.

\section{A R T I C L E H I S T O R Y}

$\begin{array}{ll}\text { Received: } & \text { 23 December } 2017 \\ \text { Revised: } & \text { 26 July } 2018 \\ \text { Accepted: } & \text { 12 August } 2018\end{array}$

\section{K E Y W O R D S}

Steel delta girder;

Flexural resistance;

Lateral-torsional buckling;

Residual stresses;

Geometric imperfections

\section{Introduction}

A Steel Delta Girder (SDG) is formed by welding two inclined rectangular plates to the compression flange and the compression portion of the web of a hot-rolled or welded I-section as shown in Figure 1. When compared to a conventional I-shaped section, SDG provides enhanced lateral and torsional stiffness that results in a noticeable increase in the lateral-torsional buckling (LTB) capacity of the beam.

Research on SDG started as early as 1961 by Hadley [1] who performed experimental tests at the University of Washington. The results of these tests has led to the construction of two bridges that employ SDG in the U.S. [2]. In the past decade, several researchers $[3,4,5,6]$ examined the flexural capacity of SDG numerically using general purpose finite element (FE) software. These studies have included both elastic and inelastic analyses. While both these analyses are needed to understand the full range of flexural behavior of SDG, the main shortcoming of these studies, especially those on the inelastic LTB capacity of SDG, is that they have ignored the effect of residual stresses $[3,6]$. However, the presence of residual stresses alters the yield pattern in the crosssection and has been shown to have an important effect on the inelastic lateral torsional buckling capacity of the beam.

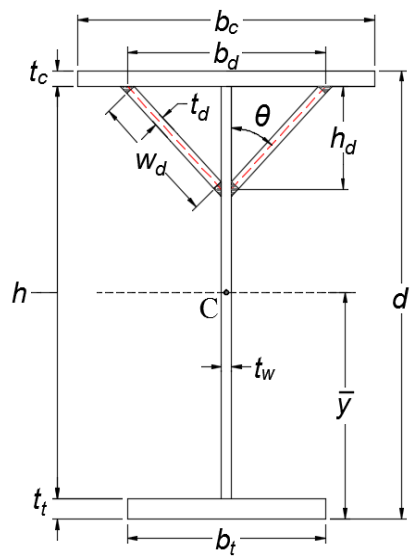

Fig. 1 A typical SDG with dimension notations

The flexural resistance curve in the current AISC specifications [7] is divided into three regions based on the unbraced length of the compression flange as illustrated in Figure 2. For relatively short-span beams or beams with continuous or closely spaced lateral supports, the beam falls into the plastic zone or what is referred to as the plateau region. The plastic zone resistance is the plastic moment capacity for compact sections, the yield moment multiplied by a web plastification factor $R_{p c}$ for non-compact sections, and the yield moment multiplied by a bending strength reduction factor $R_{p g}$ for slender sections. As the span length or distance between lateral supports increases, the beam will fail at a lower moment by inelastic LTB. Under inelastic LTB, yielding occurs in some parts of the cross-section, while other parts remain elastic. Although the actual transition from the plateau (fully plastic) region to the elastic LTB region is nonlinear, for simplicity a linear interpolation between the fully plastic and the elastic regions was adopted by AISC. For long beams or beams with a large laterally unbraced length, failure will be in the form of elastic LTB, and the theoretical elastic LTB moment is used as the nominal flexure strength of the beam. To determine the region under which a beam falls, the lateral unbraced length of the compression flange $L_{b}$ is compared against two limiting values $L_{p}$ and $L_{r}$ as shown in Figure 2. $L_{p}$ and $L_{r}$ are the limiting laterally unbraced lengths for the limit states of full cross-section yielding and inelastic lateraltorsional buckling, respectively. Depending on the type of sections, different equations for $L_{p}$ and $L_{r}$ are given by the AISC specifications. However, no expressions for $L_{p}$ and $L_{r}$ are currently available for SDG. This will be addressed in more detail in a later section of this paper.

Residual stresses and geometrical imperfections in the form of member outof-straightness play an important role in reducing the flexural capacity of beams in the inelastic range. Furthermore, the distributions and magnitudes of residual stresses vary between hot-rolled and welded sections, and hence their effect on inelastic LTB is different. In welded beams, compressive residual stresses at the tips of the flanges are generally less than those of hot-rolled beams, and thus the start of inelasticity on the compression flange is delayed. In addition, the spread of yield in the flanges of welded sections is often more rapid due to a near uniform residual stress distribution, which results in an almost uniform moment resistance of these beams in the inelastic range. This is different from hot-rolled sections in which, as mentioned earlier, the moment resistance is assumed to decrease linearly in this range. Due to the importance of the magnitudes of residual stresses and geometrical imperfections on the inelastic LTB capacity of beams, recent studies has been dedicated to the study of their effects on I-sections [8, 9].

While research on the effects of residual stresses and geometrical imperfections on I-sections are well-documented, their influence on SDG has not received much attention. A major objective of the present work is therefore to shed light on the subject by investigating how material and geometrical imperfections can affect the flexural resistance of SDG. To this end, based on an extensive literature survey a residual stress pattern that can readily be incorporated in a numerical simulation study of SDG is proposed. A threedimensional (3D) nonlinear inelastic FE model is then developed to determine the flexural resistance of SDG under uniform bending with various magnitudes of residual stresses and initial imperfections. The FE model and the modeling techniques used are verified against the experimental result of a test beam that 
failed by inelastic LTB. The numerical simulation results are compared with one another as well as against the flexural strength equations contained in the current AISC specifications. Based on these comparisons, conclusions and recommendations on the behavior and design of these SDG are provided.

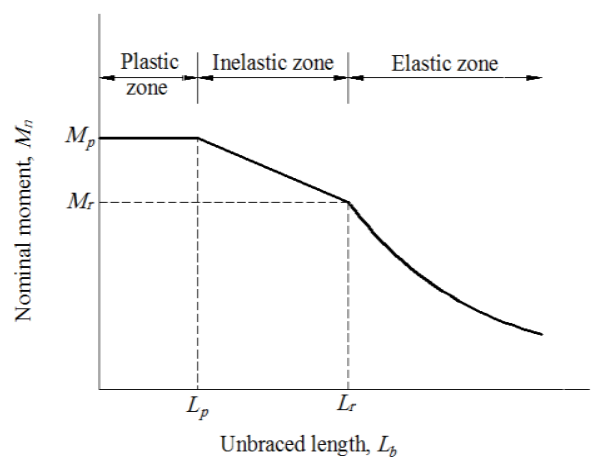

Fig. 2 Nominal moment versus unbraced length of compression flange

\section{Residual stresses}

The manufacturing process of steel sections plays an important role in the formation of residual stresses and hence the residual stress patterns are different for hot-rolled and welded I-sections. Clarin [10] and Abambres and Quach [11] provided in-depth reviews of a number of previous experimental and analytical work on residual stresses. The residual stresses in hot-rolled as well as welded doubly symmetric and monosymmetric I-sections will be discussed in this section. Note that residual stresses in high strength steel, cold-formed sections, and hot-rolled monosymmetric sections are not considered in this review.

Residual stresses in hot-rolled members are induced as a result of uneven cooling at the end of the rolling process. The main factors affecting the distribution and magnitude of residual stresses in hot-rolled members are the rolling temperature, the section geometry, the cooling conditions, the straightening procedures and the material properties $[12,13]$. Furthermore, heavy profiles tend to have higher residual stresses and a different distribution pattern due to different cooling behavior of thick plates [14]. Thus, the following review is only valid for light to medium weight sections, i.e., sections with maximum web-to-flange thickness of $25 \mathrm{~mm}$. On the other hand, cold straightening after the hot rolling process is known to reduce residual stresses in members. Because no detailed research has been reported to determine the exact influence of cold straightening [15], its beneficial effects are often conservatively ignored.

\subsection{Bisymmetric sections}

Over the years, a number of researchers have investigated residual stresses in hot-rolled bisymmetric I-sections, both experimentally and analytically. However, noticeable differences are reported in the published residual stress measurements and the proposed distribution patterns. This discrepancy could be attributed to different cooling conditions and cold-straightening techniques. Thus, a single residual stress pattern is not expected to be able to accurately predict the residual stresses present in all members. Galambos and Ketter [16] proposed a bi-linear residual stress distribution for light to medium weight Isections. This pattern has been used quite often in North America for modeling residual stresses in compact I-sections and is depicted in Figure 3(a). Young [17] proposed a parabolic distribution for residual stresses in hot-rolled I-section as shown in Figure 3(b). One common feature of these proposed residual stresses is that they were assumed to be independent of material properties as long as the yield stress is not exceeded. Furthermore, their magnitude and distribution must be such that equilibrium in the axial direction is satisfied given that these residual stresses are self-equilibrating.

Fukomoto, Itoh and Kubo [18] and Dux and Kitipornchai [19] performed experimental measurements of residual stresses in hot-rolled I-sections. The residual stress patterns so obtained are given in Figure 4. However, the authors did not propose a simplified residual stress pattern suitable for use in analytical and numerical study of its effect on beam strength. Other residual stress patterns contained in the literature include that of Trahair [20], who proposed residual stress distributions that are parabolic in the flanges and quartic in the web, and the work of Szalai and Papp [21], who proposed a quartic distribution that satisfies all equilibrium conditions including torsion and warping effects. These two polynomial residual stress distributions require lengthy computations to obtain their patterns.

The European Convention for Constructional Steelwork (ECCS) [22] proposed a bi-linear residual stress pattern for hot-rolled I-sections where the maximum compressive and tensile stresses are equal. However, ECCS makes a distinction between the magnitude of residual stresses in I-sections and $\mathrm{H}$ sections as shown in Figure 5. These proposed residual stress patterns are mostly used in Europe and were utilized in the development of the flexural resistance curves in EC3 [23].
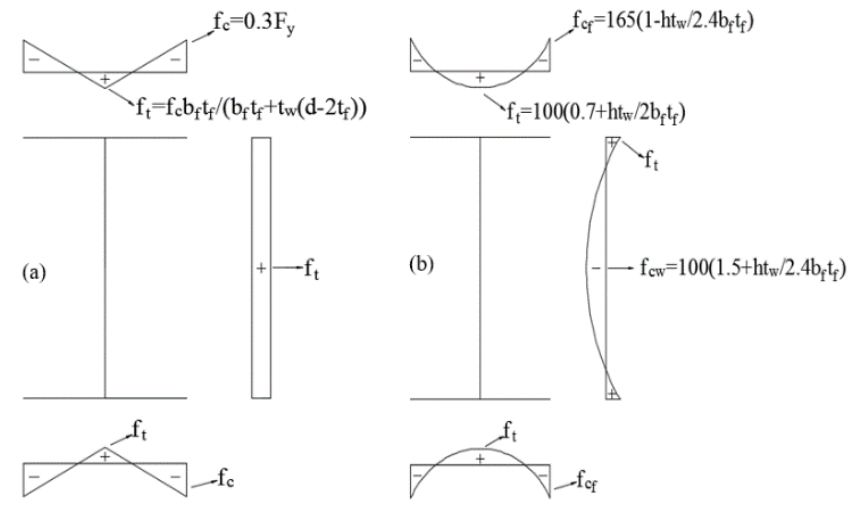

Fig. 3 Residual stress pattern by (a) Galambos and Ketter [16] and (b) Young [17]
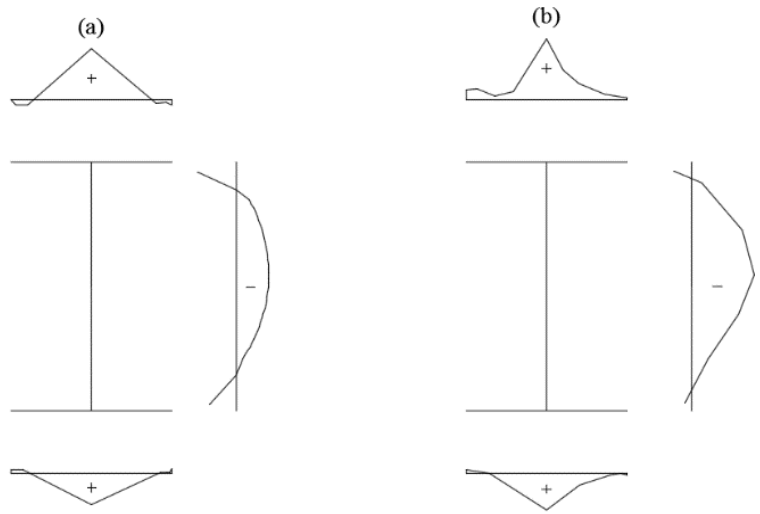

Fig. 4 Experimental residual stress patterns measured by (a) Fukomoto et al. [18] and (b) Dux and Kitipornchai [19]
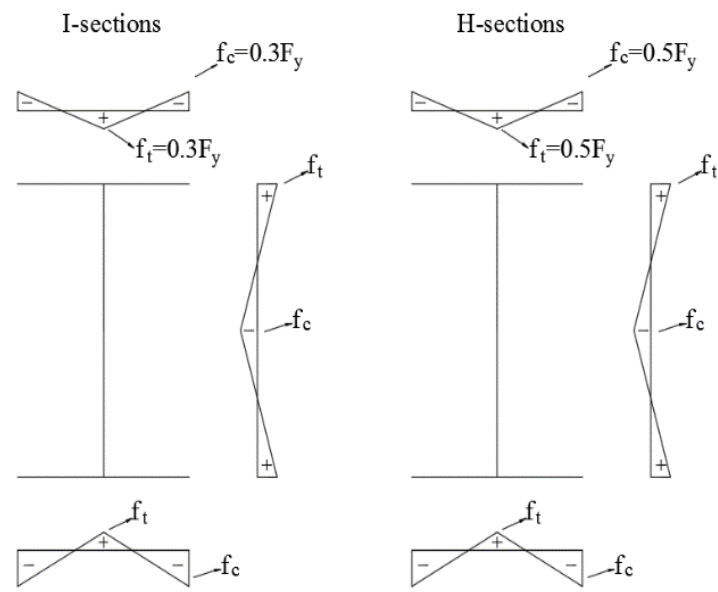

Fig. 5 Residual stress pattern proposed in ECCS [22]

Measurements of residual stresses in welded cross-sections [12, 24, 25, 26] have clearly indicated that there is a significant difference in both the magnitude and distribution pattern when compared to hot-rolled I-sections. The comparison is shown in Figure 6. Residual stresses in welded I-sections are caused mainly by locally concentrated heating which results in uneven cooling in the cross-section. The welding speed, heat input, number of passes and the technique used in cutting the plates (mill-cut or flame-cut technique) also affect the residual stress pattern and magnitude in welded sections [11]. The significant difference in residual stresses between mill-cut (mechanically cut) and flame-cut (oxygen-cut) plates is observed at the flange tips. As opposed 
to mill-cut plates, flame-cut plates have tension residual stresses at the flange tips, as illustrated in Figure 7(b), which has been found to improve LTB capacity of the girder [27].

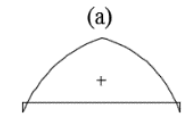

(b)
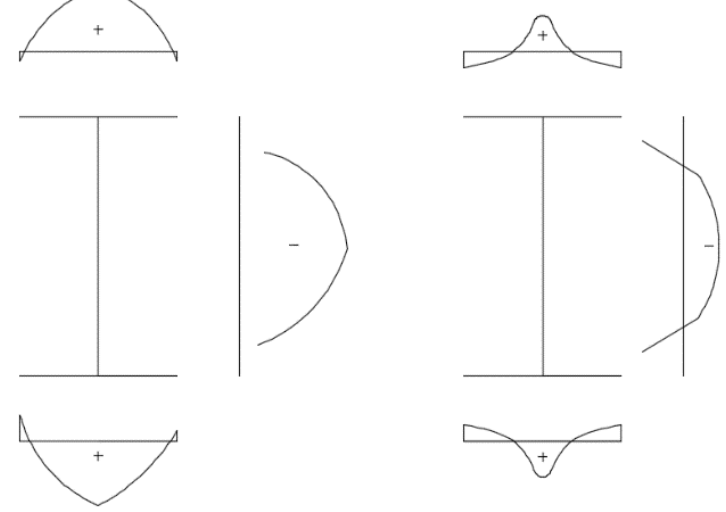

Fig. 6 Pattern of measured residual stresses (not-to-scale) of: (a) hot-rolled $10 \times 53 / 4$ UB $21[26]$ and (b) universal mill plates welded $9 \times 9[12]$ (a)

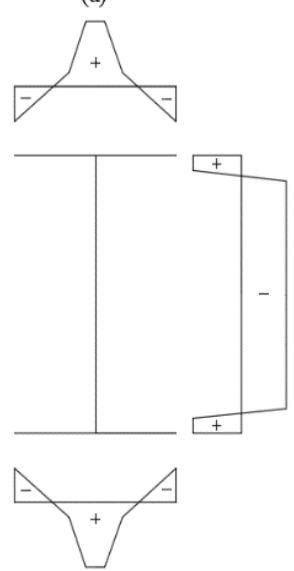

(b)

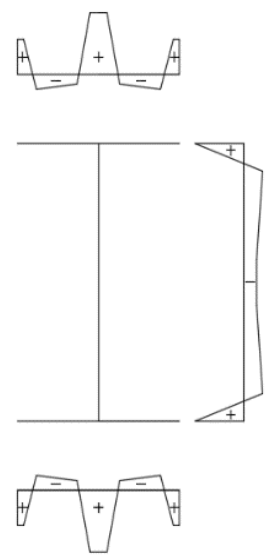

Fig. 7 Representation of measured residual stresses in (a) welded and mill-cut plates and (b) welded and flame-cut plates [27]

Other proposed residual stress patterns for welded sections include that of Dwight and Moxham [28], who proposed a rectangular tension block and related its width to either the welding size or the heat input. This pattern was supported by the work of Young and Dwight [26]. Yu and Tall [29] proposed a triangular tensile residual stress block that leads, for very short spans, to higher buckling curves compared to those obtained using the rectangular shape. Prawel, Morell and Lee [30] proposed a bi-linear residual stress pattern for welded Isection, shown in Figure 8(a), based on residual stress measurements of plates with shear cut edges. Kim [31] proposed the "best-fit" Prawel residual stress distribution, shown in Figure 8(b), where the peak stress values were reduced to match the experimental data from different sources. ECCS [22] used a trapezoidal tensile stress block and a rectangular compressive block in the flanges. Other measurements of residual stresses in welded beams have been reported by Dux and Kitipornchai [19] and Fukumoto and Itoh [32].
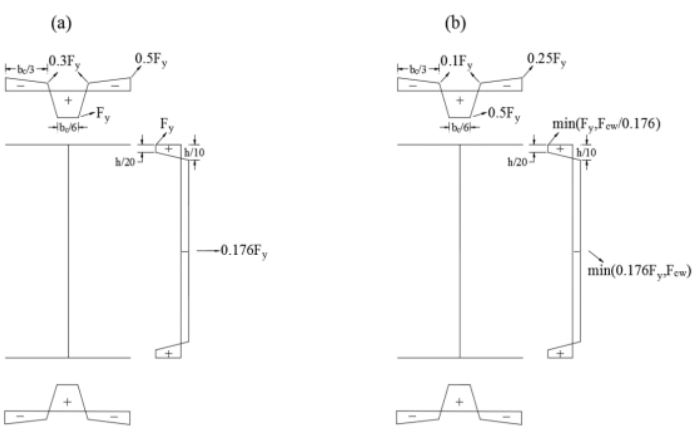

Fig. 8 Residual stress pattern reported by (a) Prawel et al. [30] and (b) Kim [31]

\subsection{Monosymmetric section}

Studies of residual stresses in welded monosymmetric beams are rather limited. Fukumoto [33] provided measured residual stresses for four monosymmetric beams as shown in Figure 9. Kitipornchai and Wong-Chung [34] suggested a residual stress pattern for welded monosymmetric beams. The pattern is shown in Figure 10(a) and is based on tendon force concept developed by White $[35,36]$. The tendon force $F$ is given by:

$F=B A_{\text {wel }}$

where $B$ is the welding process constant, and $A_{\text {wel }}$ is the area of added weld metal. In Figure 10(a), the stresses $f_{c 1}, f_{c 2}$ and the dimensions $c_{1}, c_{2}$ are functions of the tendon force $F$. This requires the area of the weld and the welding technique be known before the residual stresses in the cross-section can be calculated. Unfortunately, this information is not normally available and was not provided in the Fukumoto's tests. This renders the proposed pattern by Kitipornchai and Wong-Chung to be impractical especially for comparison with previous measurements. Trahair [37] proposed a simple residual stress pattern for welded monosymmetric beams. This is shown in Figure 10(b) where the compression residual stresses in the smaller flange were reduced. In addition, he ignored the residual stresses in the web because lateral-torsional buckling is only slightly affected by web yielding. This residual stress pattern was used in an analytical work to develop design equations for monosymmetric beams in the inelastic range.

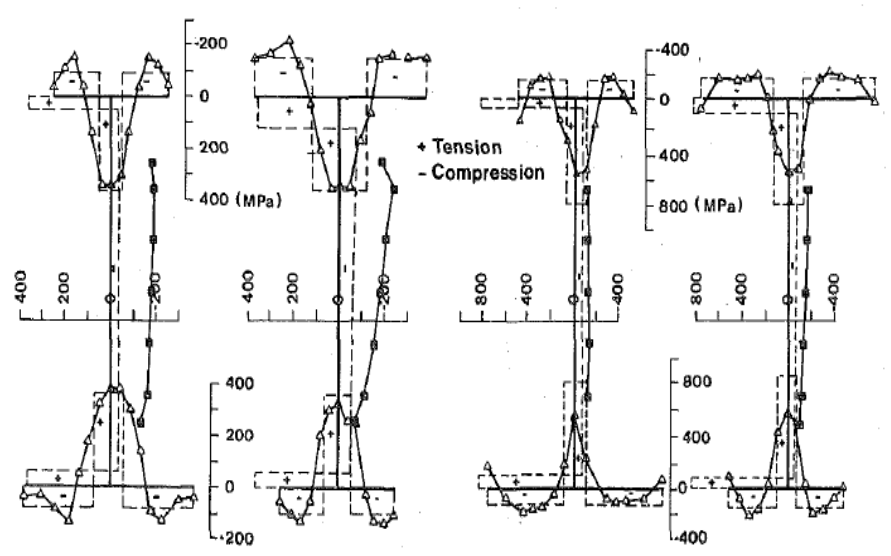

Fig. 9 Residual stresses measured for welded monosymmetric beams [33]

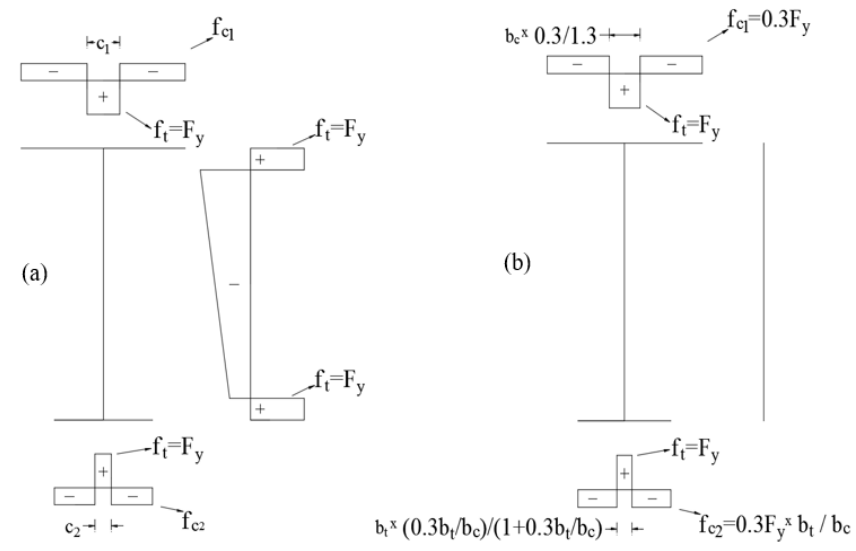

Fig. 10 Residual stress pattern proposed for welded monosymmetric beams by (a) Kitipornchai and Wong-Chung [34] and (b) Trahair [37]

\section{Proposed residual stress pattern for SDG}

From the above discussion, it can be seen that residual stress patterns in steel cross-sections are affected by a number of factors. These include, but not limited to, size and geometry of the sections, fabrication methods, rate and manner of heating and cooling, measurement techniques [38], straightening procedure, material properties, etc. However, regardless of the measured residual stress patterns, the two conditions that need to be satisfied are: (1) the maximum compressive and tensile residual stresses should not exceed the yield 
stress $F_{y}$ of the material, and (2) the residual stresses must be self-equilibrating, i.e., the sum of force over the cross-section in the longitudinal direction should be zero. These two conditions will be enforced in the proposed residual stress pattern for steel delta girders.

The addition of delta stiffeners to an I-section will affect the existing residual stresses in the girder due to the welding process. Since experimental data of residual stress measurements for SDG are not available, a residual stress pattern is to be deduced from existing patterns. This will be achieved by superimposing the residual stresses of rectangular steel plates to those of monosymmetric welded I-sections and enforcing axial or longitudinal equilibrium over the cross-section. Three different types of plates are used in welded sections: as-rolled, flame-cut, and mechanically-cut steel plates. The residual stress distributions vary among the three types of plates. The mechanically-cut steel plate refers to a shear cutting technique that does not include heat input in the process. On the other hand, flame-cut steel plates are produced by oxy-fuel cutting, laser or plasma cutting, and few other technologies that introduce intense heat input to the edges of the steel plate. This process will create high tensile stresses in the heat affected zone that often reach the yield stress of the material $F_{y}$. The penetration depth of the tensile stresses depends on various factors such as the thickness of the plate, the welding method, the number of passes, etc. Consequently, the compressive residual stresses are to be calculated so they will satisfy longitudinal equilibrium. Welding of mechanically-cut steel plates will result in a residual stress pattern similar to that of flame-cut steel plates. Thus, ECCS [22] proposes a simplified residual stress pattern shown in Figure 11 for use in steel plates that are flame-cut at both edges, or in mechanically-cut steel plates that are welded at both edges.

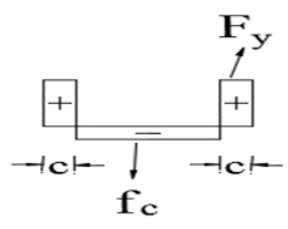

Fig. 11 Residual stresses in flame-cut plates at both edges or in mechanically-cut plates welded at both edges [22]

ECCS [22] recommends that the width of the tension block zone $c$ and the compressive residual stress $f_{c}$ be calculated using the equations:

$c=\frac{1100 \sqrt{t}}{F_{y}}$

$f_{c}=F_{y} \frac{2 c}{b-2 c}$

where $c$ is the width of each tension zone in $\mathrm{mm}, t$ is the plate thickness in $\mathrm{mm}, F_{y}$ is the steel yield stress in MPa, $f_{c}$ is the compressive residual stress, and $b$ is the total width of the steel plate.

In monosymmetric I-sections, the compressive residual stress in each flange is dependent on its relative dimensions. Two residual stress patterns for monosymmetric welded I-sections are available in the literature and have been reviewed in Section 2. The first one was proposed by Kitipornchai and Wong-Chung [34] and requires prior knowledge of the welding area and welding technique; thus, it is not very practical. The second pattern was proposed by Trahair [37] and will be used as the base pattern for SDG. A uniform compressive web residual stress equals to $0.3 F_{y}$ is added to Trahair's pattern. The width of the two tension blocks where yielding occurs in the material due to welding is obtained from longitudinal equilibrium. To superimpose the residual stress patterns of the delta stiffeners (rectangular steel plates) and the monosymmetric I-section, the following assumptions are made:

- The material yields at the locations of the welds. This is a conservative approach and is adopted in a number of proposed residual stress patterns for welded sections as discussed in Section 2.

- At the point of intersection between the delta stiffeners and the top flange, equal tension block width $c_{2}$ is assumed for both components as shown in Figure 12.

- At the point of intersection between the delta stiffeners and the web, the width of the web tension block $c_{4}$ is twice that of the delta stiffeners tension block $c_{2}$ due to having one line of weld on each side of the web.

- Once the residual stresses of the delta stiffeners are added, the widths of the compression blocks in the top flange and the web, $c_{1}$ and $c_{3}$, are obtained from longitudinal equilibrium.
The proposed residual stress pattern for SDG is shown in Figure 12. This simple pattern satisfies longitudinal equilibrium and is easy to incorporate in a FE simulation. The same pattern will be used regardless of whether the initial section is a hot-rolled or a welded I-section. The compressive residual stress values and the dimensions shown in Figure 12 are calculated using the following equations:

$f_{c 1}=0.3 F_{y}$

$f_{c 2}=\left\{\begin{array}{cc}0.3 F_{y} & \text { (equal flange size }) \\ 0.3 F_{y} \frac{b_{t}}{b_{c}} & \text { (unequal flange size })\end{array}\right.$

$f_{c 3}=F_{y} \frac{2 c_{2}}{w_{d}-2 c_{2}}$

$c_{1}=\frac{0.3}{1.3} b_{c}-2 c_{2}$

$c_{2}=1100 \frac{\sqrt{t_{d}}}{F_{y}}$

$c_{3}=\frac{0.3}{2.6} h-c_{2}$

$c_{4}=2200 \frac{\sqrt{t_{d}}}{F_{y}}$

$c_{5}=\left\{\begin{array}{c}\frac{0.3}{1.3} b_{t} \quad(\text { equal flange size }) \\ \frac{0.3 b_{t} / b_{c}}{1+\left(0.3 b_{t} / b_{c}\right)} \text { (unequal flange size) }\end{array}\right.$

where $c_{2}$ is in $\mathrm{mm}, t_{d}$ is in $\mathrm{mm}$, and $F_{y}$ is in MPa. The cross-section dimensions used in these equations are given in Figure 1.

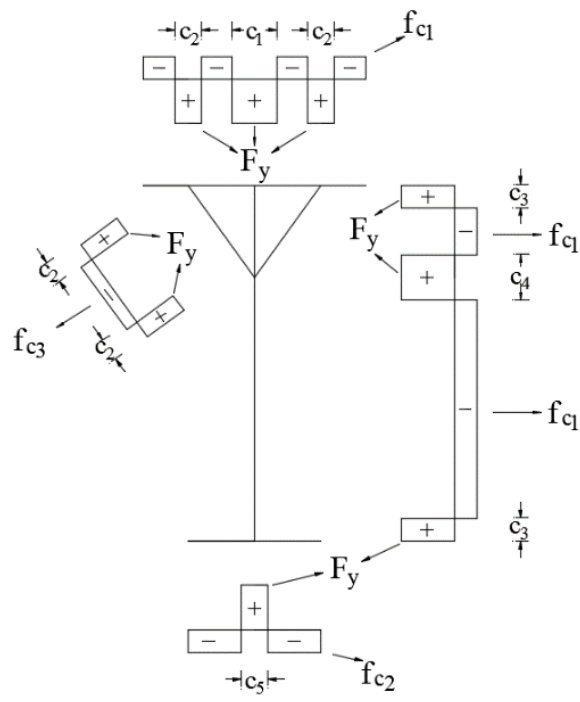

Fig. 12 Proposed residual stress pattern for SDG

\section{FE model description and validation}

\subsection{Geometry, loads, and boundary conditions}

A full nonlinear three-dimensional (3D) finite element model was developed to simulate the lateral-torsional buckling (LTB) of prismatic SDG using the general purpose commercial finite element software Abaqus version 6.14-2. The flanges, web, delta and vertical stiffeners were all modeled using 
S4R shell element, which is a 4-node shell element with reduced integration. Fork boundary conditions (flexural and torsional simply-supported) were used at both ends of the SDG and concentrated equal and opposite moments were applied at a distant reference, as shown in the structural model of Figure 13, to distribute the moment over the full cross-section near the ends. Because preliminary analyses had shown that high stress concentrations and web yielding could occur near the ends of the girder, transverse (vertical) stiffeners were provided at those locations. The transverse stiffeners were assumed to have the same thickness as the delta stiffeners and were connected to the Delta girder using the tie constraint option in Abaqus.

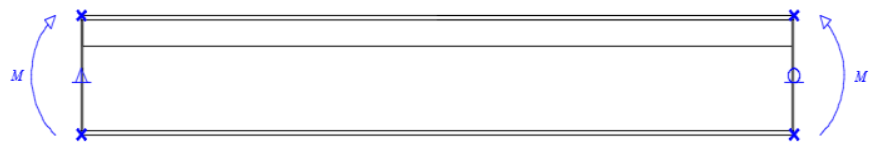

Fig. 13 Structural model used in FE simulations

\subsection{Material properties}

All plate components of the SDG were modeled using A572 Grade 50 material. The yield stress $F_{y}$ is $345 \mathrm{MPa}$ and the tensile strength $F_{u}$ is 450 $\mathrm{MPa}$. The modulus of elasticity is $200 \mathrm{GPa}$ and the Poisson's ratio is 0.3 . The following assumptions were used to generate the engineering stress-strain curve used for the analysis: (1) The stress was constant in the yield plateau region, (2) the strain at the onset of strain hardening was ten times the yield strain, (3) the strain hardening region was modeled using three straight line segments with the stress and strain at the end of the initial strain hardening region equal to $415 \mathrm{MPa}$ and $0.03125 \mathrm{~m} / \mathrm{m}$, respectively; and the stress and strain at the end of the secondary strain hardening region equal to $450 \mathrm{MPa}$ (the tensile strength) and $0.12 \mathrm{~m} / \mathrm{m}$, respectively, (4) the stress in the tertiary strain hardening region remained constant at $450 \mathrm{MPa}$. The final assumption is justified by the fact that the maximum stress reached in all simulations was much lower than the tensile strength $F_{u}$. The engineering stress-strain curve was converted, as shown in Figure 14, to true stress-strain curve prior to implementation in Abaqus.

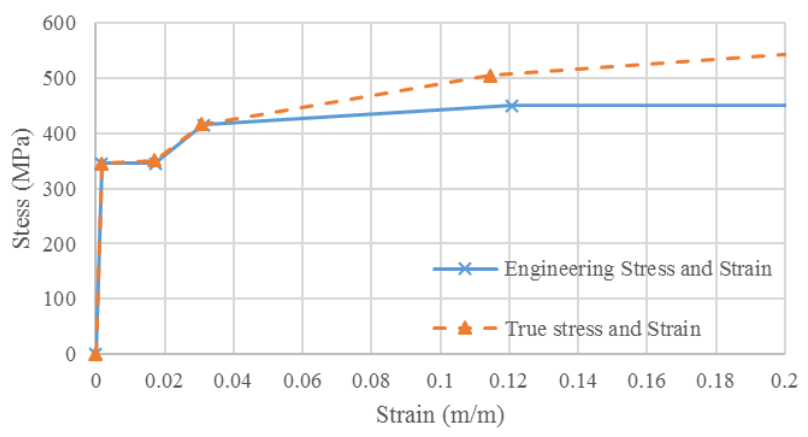

Fig. 14 Engineering and true stress-strain curves

\subsection{Modeling imperfections}

\subsubsection{Residual stresses}

The S4R shell element used in this research employs a one-point Gauss integration rule. Hence, the FE model of the SDG was meshed in accordance with the dimensions $c_{i}, i=1,2.5$ as indicated in Figure 12, to model the residual stresses in each stress block. The magnitudes of residual stresses - based on the proposed model of Section 3-were introduced in the initial analysis step using the predefined initial stress option in Abaqus as shown in Figure 15.

\subsubsection{Geometrical imperfections}

Several techniques exist for modeling initial geometrical imperfections. The most commonly used technique is to model the beam's out-ofstraightness as the first or lowest global out-of-plane buckling mode with a maximum value of $L_{b} / 1000$ (where $L_{b}$ is the unbraced length of the beam) as permitted by the AISC Code of Standard Practice [39]. Boissonnade and Somja [40] compared the different available techniques for modeling initial geometrical imperfections and concluded that using the lowest global out-ofplane buckling mode with a maximum value of $L_{b} / 1000$ was suitable for modeling geometrical imperfections. Thus, for each SDG an eigenvalue analysis was first performed. The nodal displacements of the lowest global out-of-plane buckling mode were then scaled to a maximum value of $L_{b} / 1000$ and introduced to the inelastic FE model. This FE model was used to perform the inelastic LTB analyses. The effects of the magnitude of structural imperfections on the LTB capacity will be explored in Section 5.

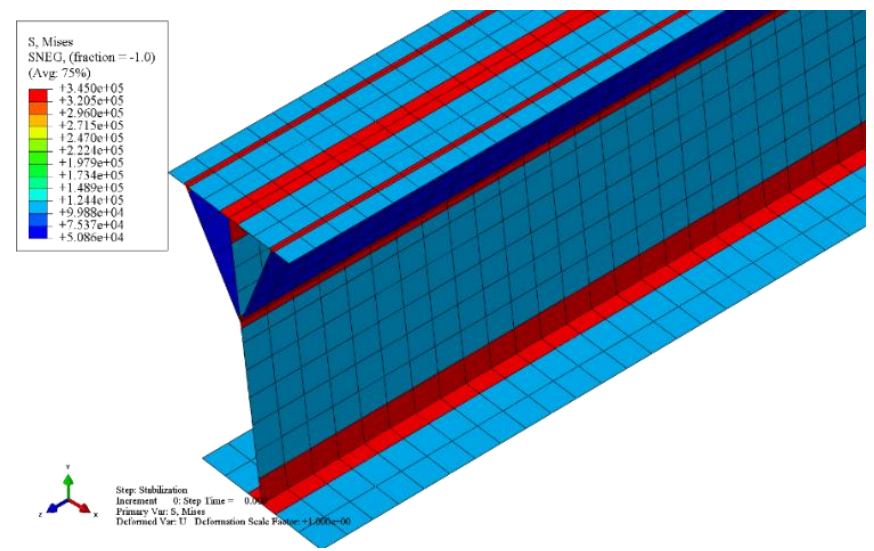

Fig. 15 Implementation of residual stresses in the FE model

\subsection{Mesh size}

Based on the results of a convergence study, the mesh size of all components of SDG has an approximate maximum element size of $5 \mathrm{~cm}$. However, the finite element mesh at some of the tension residual stress blocks requires the use of smaller element sizes so the residual stress pattern can be modeled more accurately. The number of elements used for each component of the SDG is dependent on the component's width. The convergence study has shown that the selected element dimensions are adequate to produce a good solution

\subsection{Analysis procedure}

The residual stresses are in a self-equilibrating condition when the beam is perfectly straight. However, when these stresses are applied in conjunction with initial geometrical imperfections, a general static stabilization step needs to be implemented to ensure that these stresses reach a state of equilibrium before any external loads are to be applied. The NLGEOM option in Abaqus was turned on to allow for large displacements (geometric nonlinearity). In the second step, the modified Riks buckling method was used to perform the nonlinear inelastic bucking analysis of the SDG under uniform moment. The Riks method solves for loads and displacements simultaneously, using the load magnitude as an additional unknown. Thus, an additional quantity is needed to measure the solution's progress. To do this, Abaqus uses the static equilibrium path in a load-displacement space along with the arc length. Figure 16 depicts the lateral torsional buckling (LTB) failure of one of the girders.

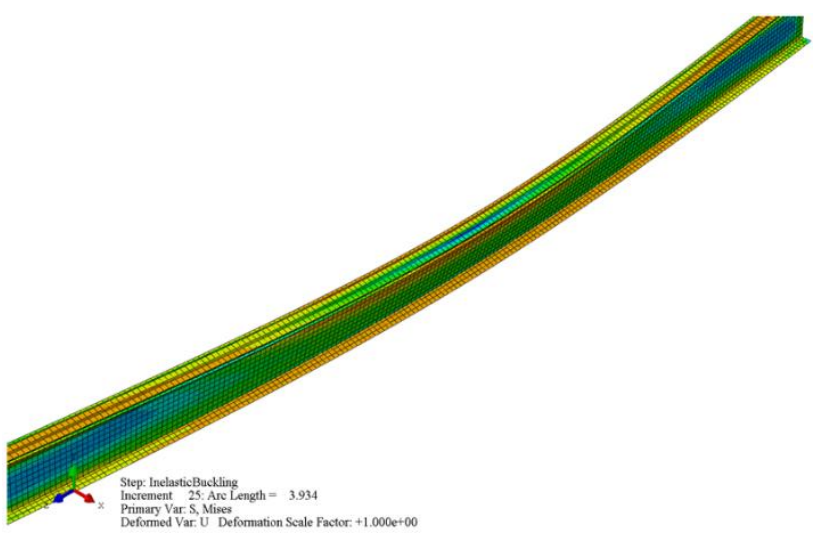

Fig. 16 Inelastic buckling failure shape of one of the girders

\subsection{Validation of the FE model}

Analytical closed-form equations for the inelastic LTB of monosymmetric beams are not available. Hence, the results of the FE model need to be verified against experimental work. The only available experimental testing on SDG was performed by Hadley [1]. The main objective of these tests was to determine whether the delta stiffeners could satisfactorily stiffen the web to 
replace the vertical stiffeners. Consequently, none of the tested girders failed by LTB and therefore cannot be used in the FE model verification.

To verify the FE model, a comparison was made between the experimental and FE simulation results of LTB tests conducted by Dux and Kitipornchai [21]. In their study, nine simply-supported beams were tested and they all failed by inelastic LTB under three different loading patterns, i.e., three different moment gradients. Figure 17 shows the three-point bending test setup selected for the FE verification. The tested beam, designated "No. 2" in the experimental work, is a hot-rolled universal 250UB37 I-section with a total span $L$ of $9 \mathrm{~m}$. Based on experimental tests and laboratory measurements, the authors provided full cross-section dimensions, residual stresses and initial imperfections measurements, and material properties for all tested girders. Hence, all these measurements and properties were incorporated in the FE model that employed the same analysis procedure, element type and mesh size used to model the SDG.

Dux and Kitipornchai [21] reported the buckling load of the test beam to be $62.6 \mathrm{kN}( \pm 0.25 \mathrm{kN}$ error margin). The buckling load obtained in the FE simulation was $60.0 \mathrm{kN}$. The difference between the experimental and the FE simulation results is $4.15 \%$. However, because the fillet areas at the junction of the web and flanges (1\% of the total area for 250UB37 section) were neglected in the FE modeling, a slightly lower buckling load than the experimental one is expected. Moreover, the use of mean values for material properties and residual stresses in the FE simulation could also lead to small errors in the comparison. This result, however, shows that the nonlinear FE model and the modeling techniques described in an earlier part of this section should provide reasonably accurate results for studying the inelastic LTB behavior of SDG.

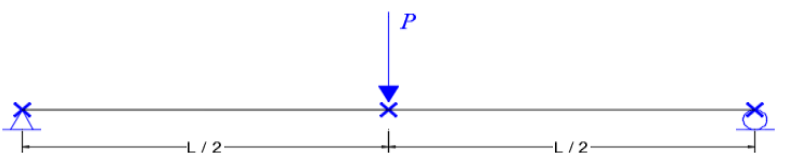

Fig. 17 Test configuration for FE verification

\section{Imperfection sensitivity study}

\subsection{Effects of geometrical imperfections and residual stresses}

This section will investigate the sensitivity of LTB strength of SDG to geometrical imperfections and residual stresses over a practical range of unsupported lengths $L_{b}$. Experimental data have shown that the measured residual stresses could be well below the recommended values in nominal residual stress patterns [21]. This can be attributed to the effects of various cold straightening techniques. In addition, Dux and Kitipornchai [21] and Essa and Kennedy [41] reported maximum initial imperfections of $L_{b} / 3300$ and $L_{b} / 2000$, respectively, in their experimental studies. On the other hand, residual stresses are sometimes completely neglected in FE analysis of LTB behavior $[6,42]$.

In this sensitivity study, a series of SDG with geometries that cover a practical range of flange and web widths and thicknesses, depths, as well as inclined stiffener width and thickness values were created. Their LTB capacities at different lateral unsupported length $L_{b}$ were obtained using FE simulations for various initial imperfection and residual stresses magnitudes. Five SDG were selected to showcase a sample of the obtained results. Their cross-section dimensions are provided in Table 1. All the FE simulations were run using flexural and torsional simply-supported boundary conditions and uniform moments as discussed in Section 4. For each SDG, three values of maximum initial imperfections were considered: $L_{b} / 1000, L_{b} / 2000$ and $L_{b} / 4000$; and two magnitudes of the proposed residual stress pattern described in Section 3 were used: Full (RS) and half (0.5RS) of its specified magnitude. This results in a total of six LTB curves for each SDG. The SDG moment capacity $M_{c r}$ versus unsupported length $L_{b}$ curves are presented in Figures 18 to 22. For purpose of comparison, the AISC [7] flexural strength $M_{n}$ curves are also plotted in these figures. However, it should be noted that the equations used to generate the AISC flexural strength curves are recommended for monosymmetric I-sections, not SDG, so some discrepancies are expected. The equations used to compute the AISC flexural strength curves are given as follows:

For $L_{b} \leq L_{p}: \quad M_{n}=M_{p}=F_{y} Z_{x} \leq 1.6 F_{y} S_{x c}$

$$
\begin{array}{ll}
\text { For } L_{p}<L_{b} \leq L_{r}: & M_{n}=\left[M_{p}-\left(M_{p}-F_{L} S_{x c}\right)\left(\frac{L_{b}-L_{p}}{L_{r}-L_{p}}\right)\right] \leq M_{p} \\
\text { For } L_{b}>L_{r}: & M_{n}=\frac{\pi^{2} E I_{y}}{L_{b}^{2}}\left\{\frac{\beta_{x}}{2}+\sqrt{\left(\frac{\beta_{x}}{2}\right)^{2}+\left[\frac{C_{w}}{I_{y}}+\frac{G J}{E I_{y}} \frac{L_{b}^{2}}{\pi^{2}}\right]}\right.
\end{array}
$$

where

$$
\begin{aligned}
L_{p} & =1.76 r_{y} \sqrt{\frac{E}{F_{y}}} \\
L_{r} & =\frac{1.38 E \sqrt{I_{y} J}}{S_{x c} F_{L}} \\
& \times \sqrt{\frac{2.6 \beta_{x} F_{L} S_{x c}}{E J}+1+\sqrt{\left(\frac{2.6 \beta_{x} F_{L} S_{x c}}{E J}+1\right)^{2}+\frac{27.0 C_{w}}{I_{y}}\left(\frac{F_{L} S_{x c}}{E J}\right)^{2}}} \\
F_{L} & =\left\{\begin{array}{c}
0.7 F_{y} \\
F_{y} \frac{S_{x t}}{S_{x c}} \geq 0.5 F_{y} \quad \text { when } \frac{S_{x t}}{S_{x c}} \geq 0.7
\end{array}\right. \\
\beta_{x} & =0.9 h_{o}\left(\frac{2 I_{y c}}{I_{y}}-1\right)\left[1-\left(\frac{I_{y}}{I_{x}}\right)^{2}\right]
\end{aligned}
$$

in which $Z_{x}$ is the plastic section modulus about the strong (bending) axis of the cross-section, $S_{x c}$ and $S_{x t}$ are the elastic section moduli with respect to the strong axis as referred to the compression and tension side of the cross-section, respectively, $I_{x}$ and $I_{y}$ are the moments of inertia about the strong and weak axis of the cross-section, respectively, $I_{y c}$ is the moment of inertia of the compression flange and the delta stiffeners about the weak axis of the cross-section, $r_{y}$ is the radius of gyration about the weak axis of the cross-section, $h_{o}$ is the distance between flange centroids, $C_{w}$ is the warping constant, $J$ is the torsional constant, $E$ is the elastic modulus, $G$ is the shear modulus, and $F_{y}$ is the nominal yield stress.

Table 1

Dimensions of SDG used in the imperfections sensitivity study (in $\mathrm{mm}$ )

\begin{tabular}{ccccccccc}
\hline 1 & $d$ & $b_{c, t}$ & $b_{d}$ & $h_{d}$ & $w_{d}$ & $t_{c, t}$ & $t_{w}$ & $t_{d}$ \\
\hline 1 & 360 & 170 & 85 & 111.5 & 105.2 & 12.7 & 8 & 8 \\
2 & 550 & 210 & 140 & 103.1 & 108.3 & 17.2 & 11 & 12 \\
3 & 390 & 300 & 150 & 70.4 & 86.9 & 19 & 11 & 12 \\
4 & 390 & 300 & 200 & 117.3 & 138.4 & 19 & 11 & 12 \\
5 & 590 & 300 & 200 & 180 & 1485.7 & 25 & 13 & 14 \\
\hline
\end{tabular}

The results of the sensitivity study show that the magnitude of residual stresses and initial imperfections affect the moment capacity as well as the shape of the LTB curve. It is observed that the nonlinearity of the curves increases when the magnitudes of residual stresses and initial imperfections decrease. In addition, the LTB curve changes from an upward concave shape to a downward concave shape. The maximum difference between the moment capacity curves is generally obtained in the middle of the inelastic range, which is in agreement with the results obtained by Nethercot [43]. As expected, the LTB curves converge at the full cross-section plastic moment capacity when $L_{b}$ is small, and become asymptotic towards the elastic LTB curves when $L_{b}$ is large. Moreover, the flexural capacity of the beam increases when the magnitudes of residual stresses and imperfections decrease. The results are consistent with the observations by Subramanian and White [9] who examined the buckling curves of hot-rolled and welded I-sections under various imperfection magnitudes. The maximum difference in the moment capacity among the six numerically obtained LTB curves for each SDG is found between the case of full magnitude residual stress along with an imperfection of $L_{b} / 1000$ and the case of half magnitude residual stress along with an imperfection of $L_{b} / 4000$. This maximum difference ranges from $12.2 \%$ to $18.2 \%$ in SDG 5 and 3, respectively. 
These results highlight the sensitivity of the LTB curves to the magnitudes of imperfections and the necessity to include residual stresses in inelastic LTB studies. Otherwise, the LTB capacity of the girders will be overestimated.

\subsection{Comparison with AISC}

When the SDG moment capacity $M_{c r}$ curves are compared with the AISC flexural strength $M_{n}$ equations, the maximum deviation of the numerically obtained moment capacity $M_{c r, F E}$ from the AISC nominal flexural strength $M_{n, A I S C}$ for each SDG-with various imperfections over the range of laterally unsupported length $L_{b}$ under investigation - are presented in Table 2 in the form of a ratio $M_{c r, F E} / M_{n, A I S C}$. The results show that when the full magnitude of residual stresses along with the largest geometrical imperfections of $L_{b} / 1000$ are used, the flexural capacity evaluated using the AISC flexural strength equations often over-predicts the moment capacity for these girders, especially for values of $L_{b}$ at the vicinity of $L_{r}$ (the limiting lateral unsupported length for inelastic lateral torsional buckling). This difference is the most noticeable in the inelastic LTB

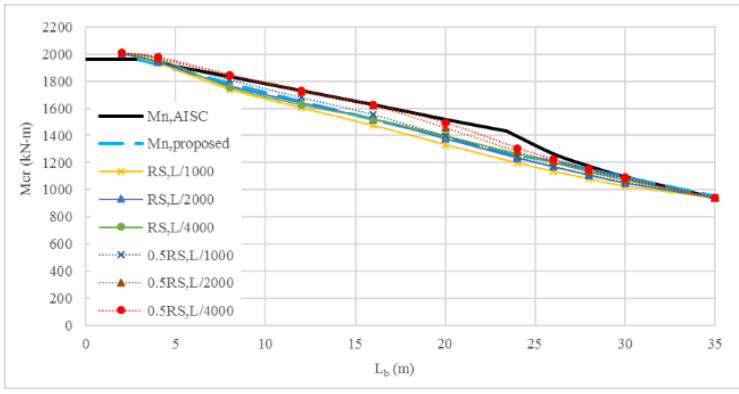

Fig. 18 LTB curves for SDG 1 with various imperfections

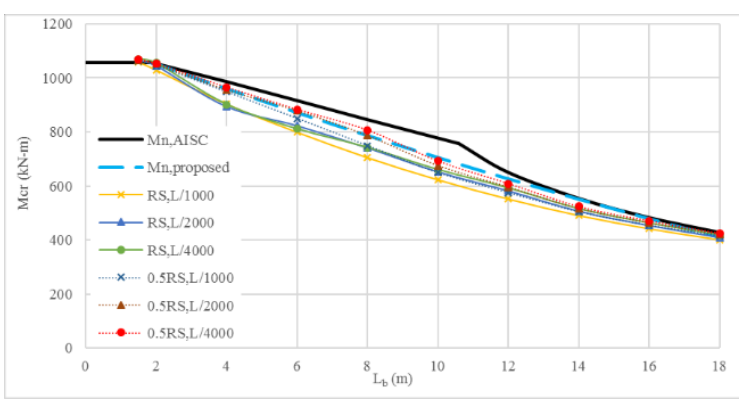

Fig. 19 LTB curves for SDG 2 with various imperfections

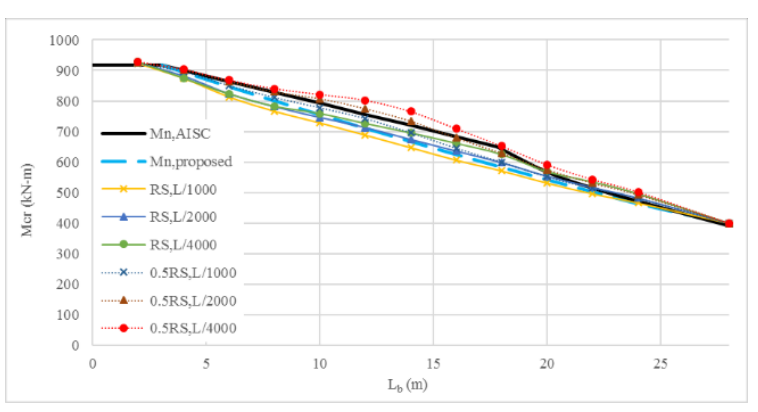

Fig. 20 LTB curves for SDG 3 with various imperfections

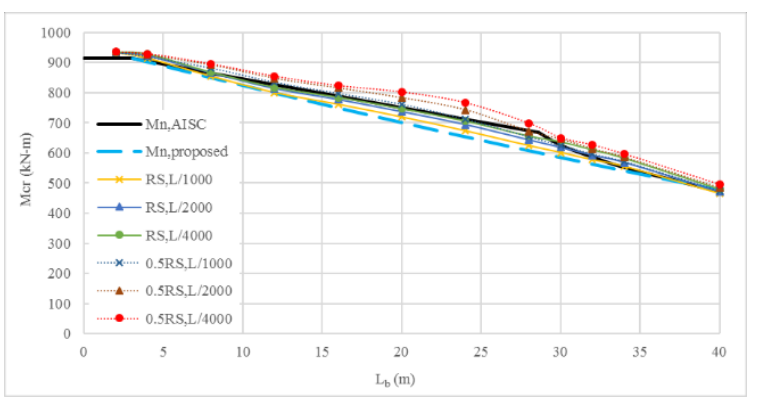

Fig. 21 LTB curves for SDG 4 with various imperfections

range and reaches a value of $20 \%$ for SDG 1 and 2. On the other hand, reducing the magnitudes of imperfections in the FE simulations could produce slightly conservative results. For instance, the results for SDG 4 with half magnitude residual stresses and initial imperfections of $L_{b} / 4000$ gives a $M_{c r, F E} / M_{n, A I S C}$ value of $8 \%$.

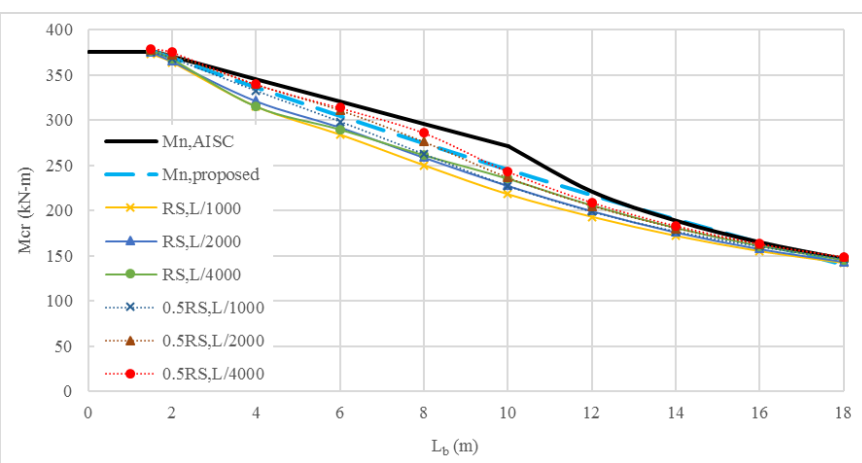

Fig. 22 LTB curves for SDG 5 with various imperfections

Table 2

$M_{c r, F E} / M_{n, A I S C}$ for each SDG under various imperfection magnitudes

\begin{tabular}{ccccccc}
\hline SDG & $\begin{array}{c}\text { RS, } \\
\text { L/1000 }\end{array}$ & $\begin{array}{c}\text { RS, } \\
\text { L/2000 }\end{array}$ & $\begin{array}{c}\text { RS, } \\
\text { L/4000 }\end{array}$ & $\begin{array}{c}0.5 \mathrm{RS}, \\
\mathrm{L} / 1000\end{array}$ & $\begin{array}{c}0.5 \mathrm{RS}, \\
\mathrm{L} / 2000\end{array}$ & $\begin{array}{c}0.5 \mathrm{RS}, \\
\mathrm{L} / 4000\end{array}$ \\
\hline 1 & 0.80 & 0.84 & 0.87 & 0.84 & 0.87 & 0.90 \\
2 & 0.80 & 0.84 & 0.85 & 0.83 & 0.87 & 0.89 \\
3 & 0.88 & 0.92 & 0.94 & 0.93 & 1.05 & 1.07 \\
4 & 0.93 & 0.95 & 0.97 & 1.04 & 1.06 & 1.08 \\
5 & 0.84 & 0.87 & 0.89 & 0.88 & 0.90 & 0.92 \\
\hline
\end{tabular}

Assuming $M_{c, F E} / M_{n, A I S C}$ follows a lognormal distribution and using only data for the more commonly encountered values for initial out-of-straightness of $L_{b} / 1000$ and $L_{b} / 2000$, the mean value for $M_{c r, F E} / M_{n, A I S C}$ was calculated to be 0.9 . Applying a steel delta girder strength reduction factor $R_{S D G}$ of 0.9 to $M_{n, A I S C}$ at $L_{r}$, and reducing this factor proportionally as $L_{b}$ decreases until it becomes 1.00 at $L_{p}$, i.e.,

For $L_{b} \geq L_{p}: \quad R_{S D G}=1.0-0.1\left(\frac{L_{b}-L_{p}}{L_{r}-L_{p}}\right)$

It can be seen from Figures 18 to 22 that the proposed flexural strength curve $M_{n, \text { proposed }}$ is more capable of predicting the flexural capacity for SDG over a large range of $L_{b}$ with different imperfections and can therefore be used for the design of these girders.

Furthermore, it is observed that the length of the plateau region from $L_{b}=0$ to $L_{b}=L_{p}$ is in fairly good agreement between the AISC equations and FE simulation results. Therefore, the expression for $L_{p}$ as given in the AISC specifications and presented in Eq. 15 can be used to determine $L_{p}$ for SDG.

However, the current AISC equation for $L_{r}$ as presented in Eq. 16 tends to under-predict the unsupported length needed for the beam to undergo elastic LTB as the numerically obtained buckling curves often require a larger $L_{r}$ value to merge with the theoretical elastic solution. This observation is in agreement with the results obtained by Subramanian and White for I-sections [9]. It is worth noting that the AISC specifications do not differentiate between hot-rolled and welded cross-sections, plus the fact that Eq. 16 is applicable only for monosymmetric I-sections, the observed error in $L_{r}$ is expected. Nevertheless, this error becomes less noticeable if the inelastic LTB region of the current AISC equation is modified by the steel delta girder strength reduction factor given in Eq. 19 and the new $L_{r}$ is now obtained as the intersection point where the modified AISC inelastic LTB line meets with the elastic LTB curve. Although experimental measurements have shown that the maximum geometrical imperfections can be below $L_{b} / 1000$ [21, 41], and Subramanian and White [9] have recommended using reduced imperfection magnitudes in FE simulations so the numerical results will match more closely with the AISC equations and experimental data, this does not preclude the possibility that other manufactured beams may reach the maximum allowable tolerance as per AISC Code of Standard Practice [39]. Therefore, to be on the conservative side and until more experimental data is available on the actual magnitude of imperfections present in beams, the authors herein still believe it 
is prudent to evaluate flexural capacity of beams using the full magnitude residual stresses and an initial imperfection not less than $L_{b} / 2000$.

\section{Summary and conclusion}

In this paper, the influence of initial geometrical imperfections and residual stresses on the flexural resistance of steel delta girders (SDG) was investigated. Previous studies on the inelastic behavior of SDG have ignored the effect of residual stresses due to a lack of knowledge of the residual stress distribution in these girders. To this end, a residual stress pattern for SDG was proposed. This pattern was developed using reported residual stress data for welded plates and monosymmetric I-sections. The proposed residual stress pattern satisfies the two important conditions of: (1) The maximum tensile and compressive residual stresses will not exceed the material yield strength, and (2) the net force acting on the section in the longitudinal direction is zero. The proposed residual stress pattern is easy to use and can readily be incorporated in FE simulations.

A nonlinear inelastic FE model was then developed and verified against the results of a test beam. Thereafter, sensitivity studies on the effects of geometrical imperfections and residual stresses were conducted. The numerically obtained moment capacity curves were first compared with one another and then evaluated against the flexural capacity curve of the AISC specifications [7]. The key observations of these studies are summarized as follows:

1. The results of the sensitivity study have shown that the effect of residual stresses must be considered in determining the inelastic LTB capacity of SDG; otherwise, the numerical results will overestimate the LTB capacity of the girder.

2. The effects of residual stresses and imperfections are most prominent in the inelastic lateral torsional buckling (LTB) region, and reducing the magnitudes of residual stresses and initial imperfections can increase the flexural resistance of the girder.

3. The moment capacity curves for each girder with various imperfection magnitudes converge at the full cross-section plastic moment capacity for small values of the lateral unsupported length $L_{b}$, and towards the theoretical elastic moment for larger values of $L_{b}$. The difference in moment capacities is most noticeable in the inelastic LTB range.

4. The magnitudes of these material and geometrical imperfections affect not only the moment capacity, but the shape of LTB curves. The nonlinearity of the curves increases when the magnitudes of these imperfections decrease.

5. When compared to the flexural strength curve of the AISC specifications, the FE simulation results show a difference of up to $20 \%$ for the case of using full magnitude residual stresses and geometrical imperfection of $L_{b} / 1000$, and approximately $8 \%$ for the case of using half magnitude residual stresses and geometrical imperfection of $L_{b} / 4000$.

6. The FE simulation results are in good agreement with the AISC suggested length for the plateau region $L_{p}$; however, the results show that the current AISC equation for $L_{r}$ provides unconservative results. A new approach to determine $L_{r}$, taken as the intersection of the modified AISC inelastic LTB line and the elastic LTB curve, is therefore proposed.

7. A steel delta girder strength reduction factor $R_{S D G}$ is proposed. When this factor is applied to the inelastic LTB region, the AISC flexural strength equations can then be used for the design of SDG.

\section{References}

[1] Hadley H.M., "Exploratory test on a steel delta girder", Civil Engineering Magazine, 50-52, 1961.

[2] Hadley H.M., "The bridge delta girder - single-webbed and doublewebbed", Engineering Journal, AISC, 132-136, 1964

[3] Arabzadeh A. and Varmazyari M., "Strength of I-girders with Delta stiffeners subjected to eccentric patch loading", Journal of Constructional Steel Research, 65, 1385-1391, 2009.

[4] Hatami F. and Esmaeili N., "Optimization of height at delta stiffened in steel girders by numerical modeling", Journal of American Science, 9(2s), 1-5, 2013.
[5] Sahnehsaraei M.J. and Erfani S., "Analysis of elastic buckling behavior of steel delta girders", International Journal of Engineering \& Technology, 3(3), 372-377, 2014.

[6] Mohebkhah A. and Azandariani M.G., "Lateral-torsional buckling of Delta hollow flange beams under moment gradient", Thin-Walled Structures, 86, 167-173, 2015.

[7] AISC, "Specification for Structural Steel Buildings (ANSI/AISC 360-16)", American Institute of Steel Construction, 2016.

[8] Chacon R., Serrat M. and Real E., "The influence of structural imperfections on the resistance of plate girders to patch loading", Thin-Walled Structures, 53, 15-25, 2012.

[9] Subramanian L., and White D.W., "Resolving the disconnects between lateral torsional buckling experimental tests, test simulations and design strength equations", Journal of Constructional Steel Research, 128, 321-334, 2017

[10] Clarin M., High Strength Steel - Local Buckling and Residual Stresses, Lic. Thesis, Sweden: Lulea University of Technology, 2004.

[11] Abambres M. and Quach W.M., "Residual stresses in steel members: a review of available analytical expressions", International Journal of Structural Integrity, 7(1), 70-94, 2016.

[12] Beedle L.S. and Tall L., "Basic column strength", Journal of the Structural Division, 86(5), 139-173, 1960

[13] Alpsten G.A., Thermal Residual Stresses in Hot-Rolled Steel Members, Fritz Engineering Laboratory Report 337.3. Bethlehem, PA: Lehigh University, 1968.

[14] Alpsten G.A. and Tall L., "Residual stresses in heavy welded shapes", Welding Journal, 49(3), 93-105, 1970.

[15] Ziemian R.D. (Ed.), Guide to Stability Design Criteria for Metal Structures, 6th Edition, John Wiley and Sons, Inc., 2010

[16] Galambos T.V. and Ketter R.L., "Columns under combined bending and thrust", Journal of the Engineering Mechanics Division, 85, 1-30, 1959.

[17] Young B.W., "Residual stresses in hot rolled members", IABSE reports of the working commissions, 23, 25-38, 1975.

[18] Fukomoto Y., Itoh Y. and Kubo M., "Strength variation of laterally unsupported beams", Journal of the Structural Division, 541-562, 1977.

[19] Dux P.F. and Kitipornchai S., "Inelastic beam buckling experiments", Journal of Constructional Steel Research, 3(1), 3-9, 1983.

[20] Trahair N.S., Flexural-torsional Buckling of Structures, E and FN Spon, 1993.

[21] Szalai J. and Papp F., "A new residual stress distribution for hot-rolled I-shaped sections", Journal of Constructional Steel Research, 61, 845-861, 2005.

[22] ECCS, Manual on Stability of Steel Strucutres", European Convention for Constructional Steelwork, Technical Committee 8, 1976.

[23] EC3, "Eurocode 3: Design of Steel Structures", Part 1-1: General Rules and Rules for Buildings (EN 1993-1-1), European Committee for Standardization (CEN), 2005.

[24] Nagaraja Rao, N.R. and Tall L., "Residual stresses in welded shapes", Welding Journal, 43(7), 295-302, 1964

[25] McFalls R.K. and Tall L., "A study of welded columns manufactured from flame-cut plates", Welding Journal, 48(4), 141-146, 1969.

[26] Young B.W. and Dwight J.B., Residual Stresses and Their Effect on the Moment-Curvature Properties of Structural Steel Sections, CIRIA Technical Note 32, Construction Industry Research and Information Association, 1971.

[27] Cherenko D.E. and Kennedy D.L., "An analysis of the performance of welded wide flange columns", Canadian Journal of Civil Engineering, 18(14), 537-554, 1991.

[28] Dwight J.B. and Moxham K.E., "Welded steel plates in compression", The Structural Engineer, 47(2), 49-66, 1969.

[29] Yu C.K. and Tall L., "Significane and application of stub column test results", Journal of the Structural Division, 97(ST7), 1841-1861, 1971

[30] Prawel S.P., Morrell M.L. and Lee G.C., "Bending and buckling strength of tapered structural members", Welding Journal, 53(2), 75-84, 1974

[31] Kim Y.D., Behavior and Design of Metal Building Frames Using General Prismatic an Web-tapered Steel I-section Members", (Doctoral Dissertation), Georgia Institute of Technology, School of Civil and Environmental Engineering, 2010.

[32] Fukumoto Y. and Itoh Y., "Statistical study of experiments on welded beams", Journal of Structural Division, 107(ST1), 89-103, 1981.

[33] Fukomoto Y., "Numerical data bank for the ultimate strength of steel structures", Der Stahlbau, 21-27, 1982

[34] Kitipornchai S. and Wong-Chung, A.D., "Inelastic buckling of welded monosymmetric Ibeams", Journal of Structural Engineering, 113(4), 740-756, 1987

[35] White J.D., Longitudinal Shrinkage of a Single Pass Weld, University of Cambridge. Report CUED/C-Struct/TR.57, 1977.

[36] White J.D., Longitudinal Stresses in Welded T-Sections, University of Cambridge. Report CUED/C-Struct/TR.60, 1977.

[37] Trahair N.S., "Inelastic buckling design of monosymmetric I-beams", Engineering Structures, $34,564-571,2012$

[38] Schajer G.S., Practical Residual Stress Measurement Methods, Wiley, 2013.

[39] AISC, Code of Standard Practice for Steel Buildings and Bridges, AISC 303-05, American Institute of Steel Construction, 2010.

[40] Boissonnade N. and Somja H., Influence of Imperfections in FEM Modeling of Lateral Torsional Buckling, Proceedings of the Annual Stability Conference, Grapevine, TX, 2012.

[41] Essa H. and Kennedy D., Distortional Buckling of Steel Beams, Structural Engineering Rep. No. 185, University of Alberta, Department of Civil Engineering, 1993

[42] Hassanein M.F., Kharoob O.F. and El Hadidy A.M., "Lateral-torsional buckling of hollow tubular flange plate girders with slender stiffened webs", Thin-Walled Structures, 65, 49-61, 2013.

[43] Nethercot D.A., "Inelastic buckling of monosymmetric I-beams", Journal of Structural Division, 99(ST7), 1696-1701, 1973. 